Egyptian Journal of Occupational Medicine, 2020; 43 (3) : 761 - 776

\title{
HEALTH HAZARDS AND SOME CORRELATES AMONG OIL REFINERY WORKERS
}

\author{
By \\ Darwish $\mathrm{MMM}^{1}$, Zayet $\mathrm{HH}^{2}$, Alhaj $\mathrm{MS}^{3}$ and Elghazally $\mathrm{SA}^{1}$ \\ ${ }^{1}$ Department of Public Health and Community Medicine, Faculty of Medicine, Assiut University, Assiut \\ ${ }^{2}$ Department of Occupational and Environmental Medicine, Cairo University, Egypt, \\ ${ }^{3}$ Ministry of Health, Yemen.
}

Corresponding author: ElghazallySA:e-mail: shima_dola@aun.edu.eg

\begin{abstract}
Introduction: Oil is a naturally occurring liquid found in rock formations. It consists of a complex mixture of hydrocarbons of various molecular weights plus other organic compounds. The workers in Aden (Yemen) Petroleum Refinery are exposed to a wide variety of hazards that may affect their health which can be broadly classified as; physical, chemical, biological, mechanical/ ergonomics and psychological hazards. Aim of work: To identify the prevalence of work-related morbidities among Aden refinery workers and to study some associated correlates. Materials and methods: A cross sectional study was conducted in Aden Refinery Company (ARC), Alburigah district, Aden governorate, Republic of Yemen and included 398 workers. Data was collected by using semi structured questionnaire which included demographic data, detailed occupational history of the current and previous jobs, and history of work related illness. Results: The mean age of the studied workers was $42.91 \pm 7.89$ years. The study showed that allergy (e.g. occupational asthma, allergic rhinitis, skin allergy etc) is the most frequently recorded illness among the study participants $(55.5 \%)$. Hypertension $(42.2 \%)$ is the second common illness among them. Hypertension and cardiovascular diseases were statistically significant higher among smokers and those with work duration of $\geq 30$ years. About one third (32.7\%) of the studied sample had medical history of post-employment hearing defects which was statistically significant among those with work duration of $\geq 30$ years, those who had history of noise exposure $(37.5 \%)$ and those who were smokers. The current study also revealed that 8 cancer cases $(2 \%)$ among the studied participants were
\end{abstract}


diagnosed post-employment. We also found that $10 \%$ of the workers were suffering from symptoms (fatigue, headache, nasal irritation and difficulty of breathing) during the working hours. Conclusion: Petroleum refinery workers are exposed to hazards that affect their health especially allergic diseases. These health effects were higher among smokers and those with long work duration ( $\geq 30$ years).

Keywords: Refinery workers, Hazards, Occupational asthma, Allergy and Hearing defect.

\section{Introduction}

The petroleum and natural gas industries play an important role in the global economy. This field is growing rapidly and offers many new job opportunities, increasing the risk of work-related death, injury and illness (Mahdi et al., 2015). Today, petrochemicals are consumed by many industries such as the automotive industry, aviation, manufacturing and power generation (Chan et al., 2017 and Siddiqui et al., 2018).

Oil refinery operations involve the conversion of crude oil (the complex mixture of hydrocarbons and inorganic compounds) into low molecular weight consumables as liquefied petroleum gas (LPG), gasoline, kerosene, diesel, naphtha and heavier hydrocarbon products (asphalt, lubricating oil and wax) at high temperatures and pressures (Varjani et al., 2017 and Chen et al., 2018).

Oil refinery workers are exposed to many risks that may affect their health in different ways. They are exposed to large varieties of many hazardous chemicals used either as process chemicals and / or present in the resulting effluents, in addition to invisible emissions, which include petroleum itself and other aromatic hydrocarbons (benzene, toluene, phenol, etc.), hydrogen sulfide and other natural gases (methane, propane, butane, etc.), carbon monoxide, asphalt, toxic heavy metals, coke dust, lead alkyls, silica and asbestos. They are also exposed to physical risks (noise, vibrations, radiation and higher temperatures) and ergonomic risks such as manual manipulation of dangerous activities, repetitive movements and uncomfortable postures (Mahdi et al., 2015).

There are two main refineries in Yemen one in Aden and the other in Mareb governorate, each of them with refining capacity more than $10,000 \mathrm{~b} / \mathrm{d}$.

The number of workers in Aden re- 
finery exceeds 4,000 workers in different departments which constitute - with their families - a relatively large sector of the Yemeni population. Thus, identifying the hazards and risk factors associated with working in petroleum refineries would prevent and control these health problems and therefore promote the health of workers. No researcher has studied the health problems of workers at oil refineries in Yemen. This study will enrich the oil sector of Yemen on the state of health of workers in this industry and will form the basis of a health promotion program for workers in this sector.

\section{Aim of work}

To assess the prevalence of workrelated morbidities among workers at the Aden refinery and identify some correlates.

\section{Materials and methods}

\section{Study design:}

It is a cross sectional study.

Place and duration of study: The present study was conducted in Aden Refinery Company (ARC) present in Aden at Alburigah district, Aden governorate, Republic of Yemen. The refinery was basically owned by the British Petroleum (BP) who established and constructed it. Data collection was carried out from June to September 2017.

\section{Study sample:}

The Company is employing about 4000 workers. Sample size was calculated Using Epi info 2000 statistical package. Using 95\% confidence interval, the calculated sample size was 351 workers which were increased to 400 to compensate for the non-response and as design effect. The researcher could reach only 398 workers using stratified random sampling technique proportionate to the numbers in different working departments; operation, maintenance, power station departments (which supply the refinery with electricity) and auxiliary departments (administrative, financial, commercial, marine and logistic supplements, firefighting, security and company's hospital).

\section{Study methods:}

Data were collected using semi structured questionnaire via personal interview and retrieval of personal records. The questionnaire was composed of 3 parts; Part I: demographic characteristics and smoking habits, Part II: post-employment clinically 
diagnosed illness (anemia, skin disease, tumors, liver diseases, hypertension, and any work- related affections) and Part III: detailed occupational history of the present occupation (duration of exposure in years, working days/ week, shift duration in hours and type of exposure) and of the previous jobs, together with details about personal protective devices.

\section{Operational definitions:}

-Tobacco smoke exposure (TSE) was calculated in "pack-year" units (Buist et al., 2007),

-Smoking categories were defined as current smoker, non-smoker (never smoked) and ex-smoker (who had given up smoking at least for 6 months),

\section{Consent}

The aim of the study explained to every participant before filling the questionnaire and verbal informed consent was obtained from all participants .Interviews took part in a private room in the refinery and confidentiality of data was assured and maintained by removing names from questionnaire and coding for identification.

\section{Ethical approval}

Reviewing the proposal was carried out before starting data collection via the Ethics Review Committee of Assiut Faculty of Medicine.

\section{Data management}

Data collection was done using personal interview and retrieval of the available records. Then coding, cleaning and statistical analysis were carried out using Statistical Package for the Social Sciences (SPSS) program version 20. Statistical presentation of data was applied; descriptive statistics (mean standard deviation, frequency distribution and percentages), appropriate significance tests were applied ( $\mathrm{t}$-test for quantitative data and chi-square for categorical data). P-value was considered significant if less than 0.05 


\section{Results}

Table (1): Demographic characteristics of the study participants.

\begin{tabular}{|c|c|c|}
\hline & No (398) & $\%$ \\
\hline $\begin{array}{l}\text { Age: (years) Mean } \pm \text { SD } \\
\text { (Range) }\end{array}$ & \multicolumn{2}{|c|}{$42.91 \pm 7.89(19.0-59.0)$} \\
\hline \multicolumn{3}{|l|}{ Sex: } \\
\hline Male & 367 & 92.2 \\
\hline Female & 31 & 7.8 \\
\hline \multicolumn{3}{|l|}{ Residence } \\
\hline Company accommodation & 32 & 8.0 \\
\hline Alburigah & 196 & 49.2 \\
\hline Al-Mansoura & 140 & 35.2 \\
\hline Others & 30 & 7.5 \\
\hline \multicolumn{3}{|l|}{ Educational level: } \\
\hline Illiterate & 2 & 0.5 \\
\hline Read \& write & 1 & 0.3 \\
\hline Basic education & 88 & 22.1 \\
\hline Secondary & 212 & 53.3 \\
\hline University & 95 & 23.9 \\
\hline \multicolumn{3}{|l|}{ Smoking status: } \\
\hline Smoker & 135 & 33.9 \\
\hline Non-smoker & 263 & 66.1 \\
\hline
\end{tabular}

Table 1 showed that the mean age of the studied workers in years was $(42.91 \pm$ 7.89). The majority of them (92.2\%) were male. About half of them reside Alburigah district and another one half completed secondary school education (49.2\% and $53.3 \%$ respectively). Two thirds of the study participants never smoked. 
Table (2): Clinically diagnosed health problems among the studied participants.

\begin{tabular}{|l|c|c|}
\hline Clinically diagnosed health problems & No $(398)$ & $\%$ \\
\hline 1 Anemia & 54 & 13.6 \\
\hline 2- Skin diseases (No.=107) & 107 & 26.9 \\
\hline Eczema & 15 & 14.0 \\
\hline Skin tags & 24 & 22.4 \\
\hline Skin allergy & 98 & 91.6 \\
\hline Skin discoloration & 43 & 40.2 \\
\hline Others & 3 & 2.8 \\
\hline 3-Malignant tumors \# & 8 & 2.0 \\
\hline 4- Hepatic insufficiency & 32 & 8.0 \\
\hline 5-Hypertension & 168 & 42.2 \\
\hline 6- Cardiovascular diseases & 48 & 12.1 \\
\hline 7- Recurrent infections & 71 & 17.8 \\
\hline 8- Allergy (other than skin) & 221 & 55.5 \\
\hline - Occupational asthma & 33 & 8.3 \\
\hline - Eye allergy & 107 & 48.4 \\
\hline - Allergic rhinitis & 174 & 78.7 \\
\hline 9- Cataract & 74 & 18.6 \\
\hline 10- Hearing defects & 130 & 32.7 \\
\hline
\end{tabular}

\#: Malignant tumors as breast, ovary, skin, colon cancer.

Table 2 showed that the allergy was the most frequently reported post-employment illness among the studied participants (55.5\%) followed by hypertension (42.2\%). About one third $(32.7 \%)$ of the sample had medical history of post-employment hearing defects.

There was statistically significant higher occurrence of hearing defects among the study participants who had occupational history of noise exposure (37.5\%) (p value $<0.001)$ (Results are not tabulated). There was also statistically significant higher occurrence of skin diseases among the study participants who had occupational history of chemicals exposure $(32.9 \%)(p$ value $=0.034)($ Results are not tabulated $)$. 
Table (3): Clinical manifestations experienced during the working time by the studied participants.

\begin{tabular}{|l|c|c|}
\hline & No (398) & \% \\
\hline $\begin{array}{l}\text { Clinical manifestations experienced during the } \\
\text { working time: }\end{array}$ & & 10.1 \\
\hline Yes & 40 & 89.9 \\
\hline NO & 358 & \\
\hline Types of clinical manifestations: & & 57.5 \\
\hline Fatigue \& headache & 23 & 7.5 \\
\hline Lack of concentration & 3 & 20.0 \\
\hline Nasal irritation \& difficulty of breathing & 6 & 15.0 \\
\hline Nervousness & & \\
\hline
\end{tabular}

Table 3 showed that about $10 \%$ of the workers were complaining of symptoms during the working hours as: fatigue and headache (57.5\%), nasal irritation and difficulty of breathing (20\%) and nervousness (15\%). 
Table (4): Distribution of post-employment health disorders among the studied participants according to their work duration.

\begin{tabular}{|c|c|c|c|c|c|c|c|}
\hline \multirow{3}{*}{ Health disorders } & \multicolumn{6}{|c|}{ Duration of working in years } & \multirow{3}{*}{ p-value } \\
\hline & \multicolumn{2}{|c|}{$<\mathbf{2 0}$} & \multicolumn{2}{|c|}{$20-<30$} & \multicolumn{2}{|c|}{$>=\mathbf{3 0}$} & \\
\hline & No & $\%$ & No & $\%$ & No & $\%$ & \\
\hline Anemia & 12 & 10.3 & 24 & 14.5 & 18 & 15.7 & 0.442 \\
\hline Skin diseases & 26 & 22.2 & 47 & 28.3 & 34 & 29.6 & 0.389 \\
\hline Hepatic insufficiency & 2 & 1.7 & 13 & 7.8 & 17 & 14.8 & $0.001 *$ \\
\hline Hypertension & 31 & 29.5 & 70 & 44.6 & 67 & 62.0 & $0.000 * *$ \\
\hline $\begin{array}{l}\text { Cardiovascular } \\
\text { diseases }\end{array}$ & 2 & 1.7 & 10 & 6.0 & 36 & 31.3 & $0.000 * *$ \\
\hline Cataract & 1 & 0.9 & 18 & 10.8 & 55 & 47.8 & $0.000 * *$ \\
\hline Recurrent infections & 19 & 16.2 & 24 & 14.5 & 28 & 24.3 & 0.090 \\
\hline Allergy \# & 59 & 50.4 & 92 & 55.4 & 70 & 60.9 & 0.278 \\
\hline Hearing defects & 13 & 11.1 & 55 & 33.1 & 62 & 53.9 & $0.000 * *$ \\
\hline
\end{tabular}

Chi square test was used \#: Allergy as: occupational asthma, allergic rhinitis, skin allergy and eye allergy.

Table 4 revealed that the post-employment health problems as hepatic insufficiency, hypertension, cardiovascular diseases, cataract and hearing defects were statistically significantly higher among those with work duration 30 years and more $(14.8 \%, 62 \%, 31.3 \%, 47.8 \%$ and $53.9 \%$ respectively) (p-values $<0.05)$. 
Table (5): Distribution of post-employment health disorders among the studied participants according to their smoking status

\begin{tabular}{|c|c|c|c|c|c|}
\hline \multirow{3}{*}{ Health disorders } & \multicolumn{4}{|c|}{ Smoking status } & \multirow{3}{*}{ p-value } \\
\hline & \multicolumn{2}{|c|}{ Smokers } & \multicolumn{2}{|c|}{ Non-smokers } & \\
\hline & No. & $\%$ & No. & $\%$ & \\
\hline Anemia & 23 & 17.0 & 31 & 11.8 & 0.148 \\
\hline Skin diseases & 41 & 30.4 & 66 & 25.1 & 0.261 \\
\hline Hepatic insufficiency & 12 & 8.9 & 20 & 7.6 & 0.656 \\
\hline Hypertension & 70 & 55.1 & 98 & 40.3 & $0.007 *$ \\
\hline Cardiovascular diseases & 24 & 17.8 & 24 & 9.1 & $0.012 *$ \\
\hline Cataract & 24 & 17.8 & 50 & 19.0 & 0.765 \\
\hline Recurrent infections & 31 & 23.0 & 40 & 15.2 & 0.056 \\
\hline Allergy \# & 90 & 66.7 & 131 & 49.8 & $0.001 * *$ \\
\hline Hearing defects & 53 & 39.3 & 77 & 29.3 & $0.044 *$ \\
\hline
\end{tabular}

Chi square test was used $\quad *$ : Statistically significant

**: Highly statistically significant \#: Allergy as: occupational asthma, allergic rhinitis, skin allergy and eye allergy.

Table 5 showed that the post-employment health problems were higher among smokers than non-smokers but the differences between them were statistically significant only for hypertension, cardiovascular diseases, allergy and hearing defects $(55.1 \%, 17.8 \%, 66.7 \%$ and $39.3 \%$ respectively) ( $p$-values $<0.05)$.

\section{Discussion}

Although petroleum is primarily a source of energy, it is also used as a raw material in the manufacture of over a thousand other products, including plastics, paints, fertilizers, detergents, cosmetics, insecticides and even food supplements. Workers at the Aden oil refinery in Yemen are exposed to a wide variety of health hazards.
The current study showed that the mean age of the studied workers was $42.91 \pm 7.89$ years (Table 1), which is slightly higher than that observed in Chinese offshore oil workers (32.4 \pm 8.6 ) (Chen et al. 2003) whereas the age range (19-59) was exactly similar to that of a study conducted in Ghana (Gyan 2013) but less than that of a study conducted on 8 refinery workers in the United Kingdom (UK) which 
was from 15-84 years (Sorahan et al, 2016) ; this could be due to difference in culture, work legislation (retirement age) and job opportunities in developing countries.

The majority of the participants in our study were men $(92.2 \%)$ (Table 1$)$, which is consistent with the results of other studies, reflecting the fact that men are offered more room for work in the industry as mentioned by Gyan 2013, in his study about the role of women in the oil Industry in Ghana and detected that oil industry require the services of men rather than women and feelings work life in the oil industry would affect women's family life . Furthermore, according to American Petroleum Institute report about women employment in petrochemical industries, females usually work in more skilled white-collar jobs as managers and other professional and administrative jobs in the industry. Since our study is about exposure to hazards in blue-collar jobs, fewer females were found (Gillula and Fullenbaum 2014).

As about the education level of workers (Table 1) in Aden refinery, $53.3 \%$ completed their secondary education; this was slightly lower compared by what was detected in a
Chinese study by Chen et al. 2003 this was $67.4 \%$. However, our results are quite different from that of another study conducted in Nigeria where the majority (73.3\%) completed their Bachelor degree or a Higher National Diploma and (18.6\%) completed the Ordinary National Diploma (equivalent to secondary education) (Francis 2014). This difference in the education distribution could be explained by being a multinational company in Nigeria compared to policy of employing Yemeni people with lower educational levels particularly with the current conflict situation in Yemen.

Regarding post-employment health effects among study participants, allergy (in the form of allergic rhinitis, skin allergy, eye allergy and occupational asthma) was the most common illness reported (55.5\%) (Table 2). Allergy was statistically significantly higher among smokers and in those who work 30 years or more (Table $4 \& 5$ ). This can be explained by the cumulative and synergistic effects of exposure to chemicals and gases over time and in addition to smoking, the condition got worse (Mahdi et al., 2015).

Ramirez et al., 2017, on their study on contamination by oil crude 
extraction-refinement and their effects on human health detected that people who live near oil fields or oil wells or who participated in oil spill cleanup activities have had different health conditions, such as irritation of skin, eyes and mucous membranes.

This is consistent also with that of Arif and Shah, (2007), who carried out a cross-sectional study on a representative sample of the American population and found that environmental exposure to volatile organic compounds (VOCs) such as benzene, toluene, polyaromatic hydrocarbons (PAHs) containing 3-5 rings of benzene which, by triggering oxidative stress in the respiratory tract, causing worsening symptoms of asthma. Exposures to these compounds over a long period of time, even in low concentration, can lead to irritantinduced asthma and skin irritation (Arif and Shah, 2007, Miller et al., 2010). Another cross-sectional study was done among 80 subjects employed in the coking unit of an oil refinery in Italy showed higher percentages of overall respiratory symptoms (cough and wheezes) and overall nasal symptoms(runny nose) among the studied population, where $33.7 \%$ suffered from respiratory symptoms and $36.2 \%$ of nasal symptoms (Minov et al., 2010).

In the current study, hypertension and other cardiovascular diseases together represented $54.2 \% \quad(42.2 \%$ and $12 \%$ respectively) (Table 2). They were significantly higher among smokers and those whose were working duration equal or more than 30 years (Table $4 \& 5$ ). Age played a confounding role with longer duration. Oil and gas workers are exposed to severe physical (noise and heat), mental stress (depression and isolation) and inappropriate dietary habits (excessive consumption of fatty foods) particularly those involved in offshore resulting in increased risk for the development of cardiovascular disease (CVD) among them (Oshaug et al., 1992). A metaanalysis of epidemiological studies has established strong and positive associations between exposure to pollutants such as polycyclic aromatic hydrocarbons, sulfur oxides, particles (PM), volatile organic compounds, polycyclic biphenyls, nitrogen oxides and ozone (O3) and increased risk of cardiovascular diseases (Hoek et al., 2013 and Bennett et al., 2014).

A cross-sectional study was conducted among workers from an oil 
, gas and energy company in Italy and found that workers, especially those over the age of 45 , had a significantly higher risk of obesity, high blood pressure, fasting hyperglycemia, high cholesterol and triglyceride levels (Mannocci et al., 2015).

These results are not limited to workers in the petroleum industry but extend to resident communities polluted by oil and gas; a cross-sectional survey in the Niger Delta region of Nigeria revealed that more than a third of the surrounding residents were hypertensive (37.4\%) (Ezejimofor et al., 2016).

In the present study, the prevalence of the impaired hearing among study participants was approximately $32.7 \%$ and the frequency was statistically significantly higher among smokers, those with working duration $\geq 30$ years and those with a history of noise exposure (37.5\%) (Table $2,4 \& 5)$. The severity of hearing defect is affected by the intensity of the noise and the duration of exposure (Mahdi et al., 2015).

An increased prevalence of hearing loss was reported after exposure to both solvents and high noise level (Morata et al., 1997). Also a study done by Sliwinska-Kowalska et al., (2004) on the effects of coexposure to noise and mixture of organic solvents on hearing in dockyard workers (701 shipyard workers) were suggesting the additive harmful effect of co-exposure to noise and organic solvents on the hearing organs.

Also the results of the current study were comparable to those of a study on refinery workers $(\mathrm{No}=438)$ in South America which reported the prevalence of hearing loss among the exposed groups ranged from $42 \%$ to $50 \%$, which is significantly exceeding that of unexposed groups (15 to 30\%) ( Morata et al., 1997).

As regards skin manifestations, the present study showed that $26.9 \%$ of study participants was complaining (Table 2) of which skin allergy was the most reported one $(91.6 \%)$, especially in people with a history of exposure to chemicals. This may be due to repeated exposure to liquid petroleum products which reach the skin and cause irritation and may be absorbed through the skin in some instances (Hahn et al., 2019). Also our results was in agreement with a study done by Harari et al., 2017 on environmental nickel exposure from oil refinery emissions: a case study in Ecuador and detected that refinery 
workers and students from neighboring schools were complaining of skin irritation.

The present work also showed that $18.6 \%$ of participants suffered from cataract, which was statistically significantly higher among people with duration of work $\geq 30$ years (Table 2). Oil refinery workers are exposed to heat, which could affect the eye lens and cause cataract. Epidemiological and clinical observations have indicated a link between exposure to heat and cataract. Workers in the molten metal industry have been reported to be at higher risk for cataract formation (Sharon et al., 2008). Also age is a confounding factor with longer duration of work.

About one in five (17.8\%) of participants suffered from repeated infections, $13.6 \%$ of them suffered from anemia and $8 \%$ of them suffered from liver insufficiency which was statistically significant among people with working duration $\geq 30$ years (Table $2 \& 4)$. The current study also reported 8 cases of cancer ( $2 \%)$ (mainly breast, ovary, skin, colon cancer) among the studied group of participants which were diagnosed after employment; however, the association of risk with cancer cannot be established due to the nature of the study as temporal sequence can't be established in this type of studies where the process of cancer may be initiated before employment and tumor markers screening is not a part of pre-employment examination)

Petroleum refineries are important sources of benzene (D'Andea and Reddy, 2014). Prolonged exposure to benzene can lead to serious adverse health effects such as hematological disorders (in the form of leukemia, lymphoma, aplastic anemia and pancytopenia), hepatotoxicity, genotoxicity, increased levels of aberrations of chromosomes and reproductive effects (Dundaroz et al., 2003, Dere and Ari, 2009, Mandiracioglu et al., 2011).

The results of the present work were matched with a study conducted in Texas in 2014 on the non-smoking population that was exposed to gasoline in the aftermath of a British oil plant fire incident, and found significant alterations in their blood and liver markers (D'Andrea and Reddy, 2014).

About $10 \%$ of workers encountered clinical manifestations during working time. It also showed that the most common manifestations were fatigue, headache, nasal irritation, difficulty breathing, and nervousness (Table 
3).This was similar to a study done by Tunsaringkarn et al,, 2012 on occupational exposure of gasoline station workers to BTEX compounds in Bangkok, Thailand on 49 workers at 6 gas stations and found that the most common symptoms among the studied workers were headache (61\%), fatigue (29\%), and throat irritation (11\%), respectively. Exposure to hydrocarbons (such as gasoline and toluene) has been linked to fatigue and some effects of the nervous system (such as headache, nausea, dizziness).

\section{Conclusion:}

Oil refinery workers are exposed to different types of health hazards. Allergy, hypertension and the hearing problems were the most reported health effects among the studied participants. In addition, these workers are exposed to certain petroleum products such as polycyclic aromatic hydrocarbons which have serious adverse health effects and can be carcinogenic. Smoking and longer duration of work have both cumulative and synergistic effects.

\section{Recommendations:}

Intervention programs with oil refiners are needed to reduce the effects of these hazards, as well to reduce smoking among workers. An electronic medical registration system and followup studies are recommended to establish the correlation and causation between different exposures and outcomes. Environmental monitoring studies are also recommended.

\section{Conflict of interest}

No conflict of interest is declared by all authors

\section{Funding}

This study did not receive any funding from any source.

\section{Acknowledgement}

The authors would like to acknowledge the contribution of all individuals who participated in this study.

\section{References}

1. Arif AA and Shah SM(2007): Association between personal exposure to volatile organic compounds and asthma among US adult population. Int Arch Occup Environ Health; 80(8):711-9.

2. Bennett $\mathrm{O}$, Kandala NB, Ji C, Linnane J and Clarke A (2014): Spatial variation of heart failure and air pollution in Warwickshire, UK: an investigation of small scale variation at the ward-level. BMJ open; 4(12): e006028.

3. Buist AS, McBurnie MA, Vollmer WM, Gillespie S, Burney P, et al(2007): In- 
ternational variation in the prevalence of COPD (the BOLD Study): a population-based prevalence study. The Lancet; 370(9589):741-50.

4. Chan KL, Wang S, Liu C, Zhou B, Wenig MO et al. (2017): On the summertime air quality and related photochemical processes in the megacity Shanghai, China. Sci Total Environ; 580:974-83.

5. Chen CF, Chio CP, Yuan TH, Yeh YP and Chan CC (2018): Increased cancer incidence of Changhua residents living in Taisi Village north to the No. 6 Naphtha Cracking Complex. J Formos Med Assoc; 117(12):1101-7.

6. Chen WQ, Wong T, Yu T, Lin Y, Lee w ,et al. (2003): Determinants of perceived occupational stress among Chinese offshore oil workers. Work Stress; 17(4): 287-305, doi: 10.1080/02678370310001647302.

7. D'Andrea MA and Reddy GK(2014): Hematological and hepatic alterations in nonsmoking residents exposed to benzene following a flaring incident at the British petroleum plant in Texas City. Environ Health; 13(1):115.

8. Dere E and Ari F(2009): Effect of benzene on liver functions in rats (Rattus norvegicus). Environ Monit Assess; 154(1-4):23-7.

9. Dundaroz M, Turkbay T, Akay C, Sarici S, Aydin A, et al. (2003): Antioxidant enzymes and lipid peroxidation in adolescents with inhalant abuse. Turk J Pediatr; 45(1):43-5.

10. Ezejimofor MC, Uthman OA, Maduka O, Ezeabasili AC, Onwuchekwa AC, et al (2016): The burden of hypertension in an oil-and gas-polluted environment: a comparative cross-sectional study. Am J Hypertens ; 29(8):925-33.

11. Francis U (2014): Organizational Citizenship Behaviour and Demographic Factors among Oil Workers in Nigeria. IOSR Jour- nal of Humanities and Social Science; 19 (8): $87-95$

12. Gillula J and Fullenbaum R (2014): Minority and Female Employment in the Oil \& Gas and Petrochemical Industries. American Petroleum Institute. IHS Global Inc. 1150 Connecticut Ave, NW, Suite 401 Washington, D.C. 20036

13. Gyan C (2013): The Role of Women in the oil Industry. J Soc Sci; 9 (3): 94-100. doi:10.3844/jsssp.2013.94.100

14. Hahn T, Botzenhart $\mathrm{K}$ and Schweinsberg F (2019):Toxic Effects of Solvent Exposure. Handbook of Solvents. Use, Health, and Environment; 2:1347.

15. Harari R, Harari F and Forastiere F (2017): Environmental nickel exposure from oil refinery emissions: a case study in Ecuador. Ann Ist Super Sanita; 52(4):495-9.

16. Hoek G, Krishnan RM, Beelen R, Peters A, Ostro B, et al(2013): Long-term air pollution exposure and cardio-respiratory mortality: a review. Environ Health; 12(1):43.

17. Mahdi G, Setareh S and Sadry (2015):Employees occupational diseases: reference to oil and gas companies. Indian Journal of Fundamental and Applied Life Sciences; 5(S1):4317-22.

18. Mandiracioglu A, Akgur S, Kocabiyik N and Sener U(2011):Evaluation of neuropsychological symptoms and exposure to benzene, toluene and xylene among two different furniture worker groups in Izmir. Toxicol Ind Health; 27(9):802-9.

19. Mannocci A, Pignalosa S, Saulle R, Sernia S, Sanctis SD, et al(2015): Prevalence of major cardiovascular risk factors among oil and gas and energy company workers. Ann Ist Super Sanita; 51:148-53.

20. Miller RL, Garfinkel R, Lendor C, Hoepner L, Li Z, et al(2010): Polycyclic aromatic hydrocarbon metabolite levels and pediatric 
allergy and asthma in an inner-city cohort. Pediatr Allergy Immunol; 21(2p1):260-7.

21. Minov J, Karadzinska-Bislimovska J, Vasilevska K, Trajceva L, Risteska-Kuc S, et $\mathrm{al}(2010)$ : Respiratory and nasal symptoms, immunological changes and lung function among petroleum refinery workers. Med Lav; 101(5):364-74.

22. Morata TC, Engel T, Durão A, Costa TR, Krieg EF, et al(1997): Hearing loss from combined exposures among petroleum refinery workers. Scand Audiol; 26(3):141-9.

23. Oshaug A, Østgård L and Trygg K (1992): Diet among oil-workers on off-shore oil installations in the Norwegian sector of the North Sea. Br J Nutr; 68(1):11-9.

24. Ramirez MI, Arevalo AP, Sotomayor S and Bailon-Moscoso N (2017): Contamination by oil crude extraction-Refinement and their effects on human health. Environ pollut; 231:415-25.

25. Sorahan T and Mohammed N (2016): Incidence of myelodysplastic syndrome in UK petroleum distribution and oil refinery workers, 1995-2011. Int J Environ Res Public Health; 13(5): 474-81

Doi: 10.3390/ijerph13050474

26. Sharon N, Bar-Yoseph PZ, Bormusov
E and Dovrat A (2008): Simulation of heat exposure and damage to the eye lens in a neighborhood bakery. Exp Eye Res; 87(1):49-55.

27. Siddiqui A, Verma $M$ and Verter V(2018): An integrated framework for inventory management and transportation of refined petroleum products: Pipeline or marine? Appl Math Model; 55:224-47.

28. Sliwinska-Kowalska M, Zamyslowska-Szmytke E, Szymczak W, Kotylo P, Fiszer M, et al(2004): Effects of coexposure to noise and mixture of organic solvents on hearing in dockyard workers. J Occup Environ Med; 46(1):30-8.

29. Tunsaringkarn T, Siriwong W, Rungsiyothin A and Nopparatbundit S(2012): Occupational exposure of gasoline station workers to BTEX compounds in Bangkok, Thailand. Int J Occup Environ Med (The IJOEM);3(3):117-25

30. Varjani SJ, Gnansounou E and Pandey A(2017): Comprehensive review on toxicity of persistent organic pollutants from petroleum refinery waste and their degradation by microorganisms. Chemosphere; 188:280-91. 